\title{
PERANCANGAN SISTEM PEMPROSES TRANSAKSI PENJUALAN SUKU CADANG MESIN OUTBOAT PADA CV. DINAMIKA MARINE
}

\author{
Efrizal $^{1 *}$ \\ ${ }^{1}$ Program Studi Manajemen Informatika, Fakultas Ilmu Komputer, \\ AMIK Indonesia, Jl. T Nyak Arief Sp Mesra No. 400, Kota Banda Aceh, Indonesia \\ Email: efrizal101@gmail.com ${ }^{1 *}$
}

\begin{abstract}
Abstrak
Tujuan dari penelitian ini adalah; 1) Untuk mengetahui Perancangan Sistem Pemproses Transaksi Penjualan Suku Cadang Mesin Outboat pada CV. Dinamika Marine, 2) Untuk merancang Sistem Pemproses Transaksi Penjualan Suku Cadang Mesin Outboat pada CV. Dinamika Marine berbasis web, DAN 3) Rancangan yang dibangun nantinya merupakan prototype transaksi penjualan yang berjalan pada sistem operasi windows dan tidak membutuhkan sebuah koneksi internet. Dalam pembuatan model ini peneliti menyusun diagram alir data yang digunakan adalah diagram alir data logika untuk menggambarkan sistem yang akan diusulkan, sedangkan pada proses Pengembangan prototipe menggunakan metode waterfall. hasil peneltiain diantaranya; 1) Aplikasi Penjualan Suku Cadang Mesin Outboat ini mempermudah dalam pengolahan data transaksi dan data stok barang berdasarkan penjualan, terlebih dahulu dilakukan analisa sistem lama, analisa kebutuhan pengguna, penganalisisan kelayakan sistem, perancangan desain sistem yang meliputi pemodelan proses dengan DAD sebagai alat bantu desain, pemodelan data dengan membuat rancangan tabel, dan perancangan antarmuka design interface dan dibangun menggunakan bahasa pemrograman berbasis web dengan database yang dibuat menggunakan MySQL, dan 2) Tingkat ketelitian aplikasi ini dalam hal pencatatan tranksaksi dan stok Suku Cadang Mesin Outboat dapat dilihat berdasarkan hari, bulan dan tahun tertentu sehingga dapat mengurangi tingkat kesalahan human error. Aplikasi ini dapat menangani perubahan-perubahan yang terjadi, seperti perubahan harga dan penambahan jenis barang, perubahan-perubahan tersebut dapat dilakukan pengolahan pada form transaksi penjualan. Aplikasi bersifat sederhana, bahasa yang digunakan mudah dimengerti user, sehingga tidak memerlukan waktu yang lama untuk pelatihan dalam pengoperasian aplikasi ini.
\end{abstract}

Kata Kunci: Perancangan; Sistem Pemproses Transaksi; Penjualan; Suku Cadang; Mesin Outboat.

\begin{abstract}
The aim of this research is; 1) To find out the Design of Outboat Engine Parts Sales Transaction Processing System on CV. Dinamika Marine, 2) To design a Transaction Processing System for Sales of Outboat Engine Parts on CV. Web-based Marine Dynamics, AND 3) The design that will be built later is a sales transaction prototype that runs on the Windows operating system and does not require an internet connection. In making this model, the researcher compiled a data flow diagram that used a logical data flow diagram to describe the system to be proposed, while the prototype development process used the waterfall method. the results of the research include; 1) This Outboat Engine Spare Parts Sales application makes it easier to process transaction data and stock data based on sales, firstly the old system analysis, a user needs analysis, system feasibility analysis, system design which includes process modeling with $\mathrm{DAD}$ as a design tool, data modeling by making table designs, and designing interface designs and built using a web-based programming language with a database created using MySQL, and 2) The level of accuracy of this application in terms of recording transactions and stocks of Outboat Engine Parts can be seen by day, month and certain years so as to reduce the level of human error. This application can handle changes that occur, such as price changes and additional types of goods, these changes can be processed on the sales transaction form. The application is simple, the language used is easy for the user to understand, so it does not require a long time for training in operating this application.
\end{abstract}

Keyword: Design; Transaction Processing System; Sale; Parts; Outboat Engine. 


\section{Pendahuluan}

Semakin pesatnya pertumbuhan dan perkembangan pembangunan di Indonesia yang berorientasi kepada teknologi canggih baik di bidang industri maupun di bidang usaha [1,2], khususnya dalam menghadapi era globalisasi bebas saat ini maka dibutuhkan tenaga kerja berkualitas [3,4,5]. Pada saat ini kemajuan teknologi sangat berpengaruh terhadap berbagai bidang kehidupan manusia $[6,7,8]$, sehingga meninbulkan dampak positif bagi perkembangan teknologi di lingkungan masyarakat terutama di bidang informasi $[9,10]$.

CV. Dinamika Marine yang memiliki bidang usaha penjualan yang membutuhkan sistem penjualan. Akan tetapi, untuk saat ini CV. Dinamika Marine belum memiliki sebuah sistem khusus untuk mencatat transaksi dan membuat laporan baik penjualan suku cadang untuk membuat laporan data suku cadang dan transaksi penjualan masih menggunakan tenaga manusia seutuhnya yakni pencatatan manual dalam buku transaksi sehingga persentase kesalahan yang terjadi semakin tinggi.

Untuk mengatasi masalah-masalah tersebut, penulis mencoba untuk memberikan solusi melalui suatu rancangan sistem baru, yakni dengan penggunaan teknologi informasi berbasis komputer yang penulis harapkan bisa memberikan pemecahan masalah terhadap pencatatan transaksi, khususnya dalam dalam transaksi penjualan suku cadang yang kemudian diharapkan hal yang berkaitan dengan data suku cadang dan transaksi bisnis dapat di proses dengan cepat, tepat dan akurat. Adapun tujuan dari penelitian ini adalah; 1) Untuk mengetahui Perancangan Sistem Pemproses Transaksi Penjualan Suku Cadang Mesin Outboat pada CV. Dinamika Marine, 2) Untuk merancang Sistem Pemproses Transaksi Penjualan Suku Cadang Mesin Outboat pada CV. Dinamika Marine berbasis web, DAN 3) Rancangan yang dibangun nantinya merupakan prototype transaksi penjualan yang berjalan pada sistem operasi windows dan tidak membutuhkan sebuah koneksi internet.

\section{Metode Penelitian}

Dalam pembuatan model ini peneliti menyusun diagram alir data yang digunakan adalah diagram alir data logika untuk menggambarkan sistem yang akan diusulkan $[11,12]$. Penekanannya pada logika dari kebutuhan-kebutuhan sistem [13], yaitu proses-proses apa secara logika yang dibutuhkan oleh sistem. Komponennya adalah :

a) Kesatuan Luar (External entity).

Kesatuan luar merupakan kesatuan (entity) di lingkungan luar sistem yang dapat berupa orang, organisasi atau sistem lainnya yang berada di lingkungan luarnya yang akan memberikan input atau menerima output dari sistem [15].

b) Arus Data (Data flow)

Arus data menunjukkan arus dari data yang dapat berupa masukan untuk sistem atau hasil dari proses sistem. Arus data ini mengalir diantara proses, simpanan data dan kesatuan luar [11].

c) Proses (Process)

Proses adalah kegiatan atau kerja yang dilakukan oleh orang, mesin atau komputer dari hasil suatu arus data yang masuk ke dalam proses untuk dihasilkan arus data yang akan keluar dari proses [11].

d) Simpanan Data (Data Store)

Simpanan data merupakan simpanan dari data yang berupa suatu file atau database di sistem computer [15].

Sedangkan pada proses pengembangan prototipe menggunakan metode waterfall. Proses penjualan suku cadang mesin outboat pada CV. Dinamika Marine pada dasarnya telah menggunakan komputer. pendataan penjualan, selanjutnya bagian mengirimkan form Penjualan khususnya penjualan untuk mengisi data kelengkapan lainnya. Selanjutnya setelah semua data lengkap, bagian administrasi membuat laporan rekapitulasi mengenai data penjualan tersebut, agar 
lebih jelas sistem penjualan suku cadang mesin outboat dapat dilihat di diagram konteks dibawah ini:

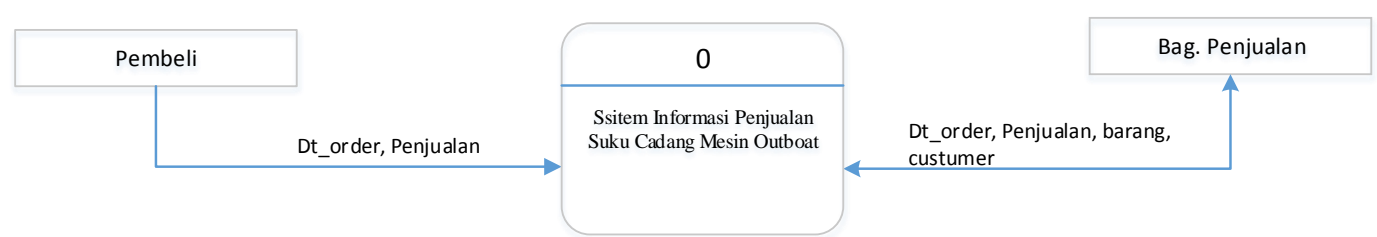

Gambar 1. Diagram Konteks

Pada gambar 1 diagram konteks, pembeli melakukan pengecekan barang pada system, apabilan barang dibeli maka akan melakukan transaksi pembelian dan bagian penjualan melakukan proses transaksi hingga pengiriman barang. Sedangkan proses dalam penjualan suku cadang mesin outboat dapat dilihat pada gambar berikut ini :

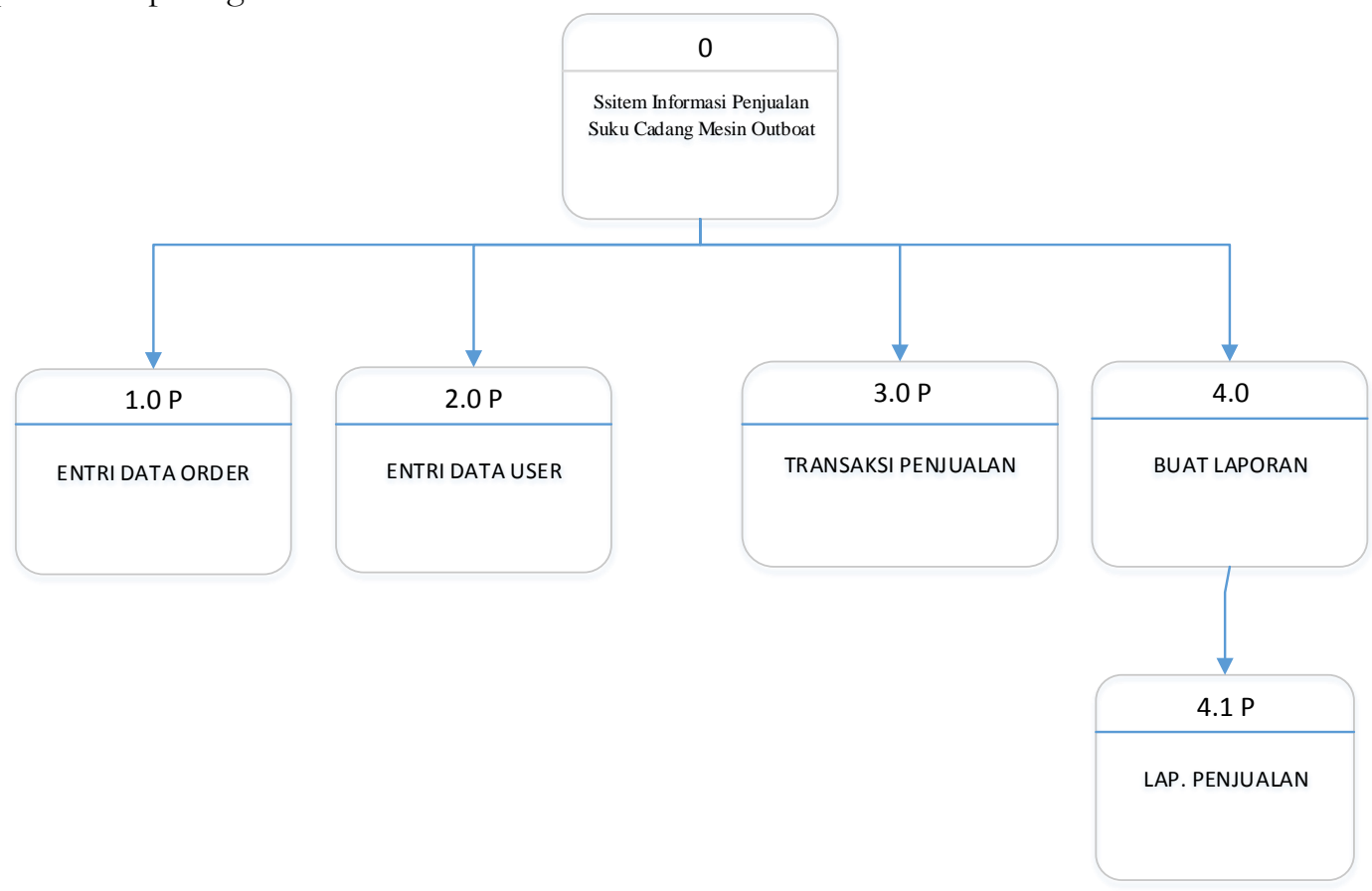

Gambar 2. Diagram Berjenjang

Berdasarkan gambar 2 terlihat bahwa pada setiap penjualan suku cadang mesin outboat pada CV. Dinamika Marine terdapat empat proses. keempat proses tersebut adalah Entry Data Order Hp, Entry Data User, Transaksi Penjualan dan Buat Laporan. Untuk lebih jelasnya, antara satu proses ke proses lainnya dapat dilihat pada gambar 3 . 


\section{Jurnal Indonesia : Manajemen Informatika dan Komunikasi}

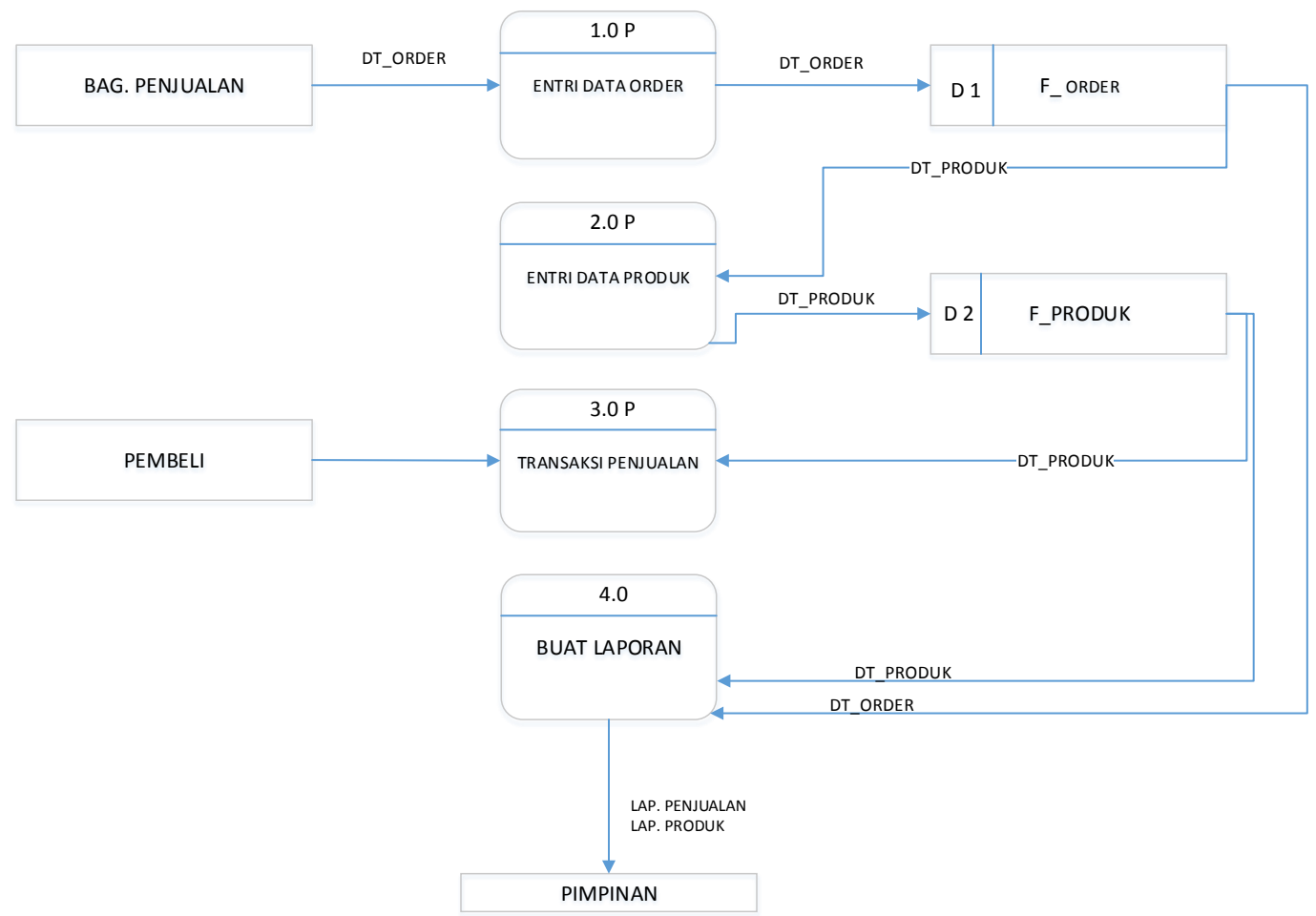

Gambar 3. Diagram arus data level 0 sistem berjalan

Berdasarkan gambar 3 dapat dijelaskan proses pendataan penjualan, petugas mencatat data penjualan. Proses dari pencatatan Penjualan akan dilaporkan secara periodik kepada Pimpinan.

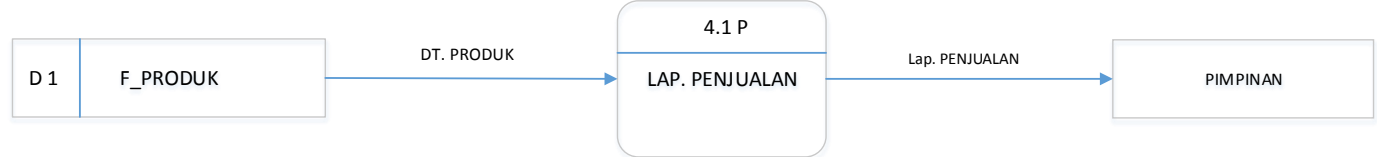

Gambar 4. Diagram arus data level 1 proses nomor 4 rancangan sistem

Berdasarkan gambar 4 dapat dijelaskan bahwa masing-masing file data memberikan data kepada proses pembuatan laporan, dari setiap proses pembuatan laporan memberikan masingmasing laporan kepada Pimpinan, proses pembuatan data Penjualan.

\section{Hasil dan Pembahasan}

Adapun hasil penelitian berupa prototipe aplikasi sistem pemproses transaksi penjualan suku cadang mesin outboat, yang terdiri form login, halaman utama, penjualan, daftar penjualan, pemesanan, rekap penjualan, pencarian, invoice, kalender transaksi, dan laporan detail penjualan. Berikut ini adalah hardware dan software yang dibutuhkan untuk menggunakan program sistem Penjualan, yaitu:

a. Hardware

Hardware yang dapat mendukung aplikasi ini memerlukan perangkat keras dengan spesifikasi:

1) CPU minimal pentium 3 dengan kecepatan $633 \mathrm{Mhz}$

2) Ram $256 \mathrm{MB}$

3) Hard disk minimal 1 GigaByte

4) Monitor

5) Keyboard dan Mouse.

6) Printer 


\section{b. Software}

Software yang mendukung aplikasi ini diantaranya:

1) Windows 7,8,10, Linux, Symbian, Android

2) Browser (Mozilla, Google Chrome)

3) Xampp

Sedangkan hasil rancangan struktur menu aplikasi sebagai berikut:

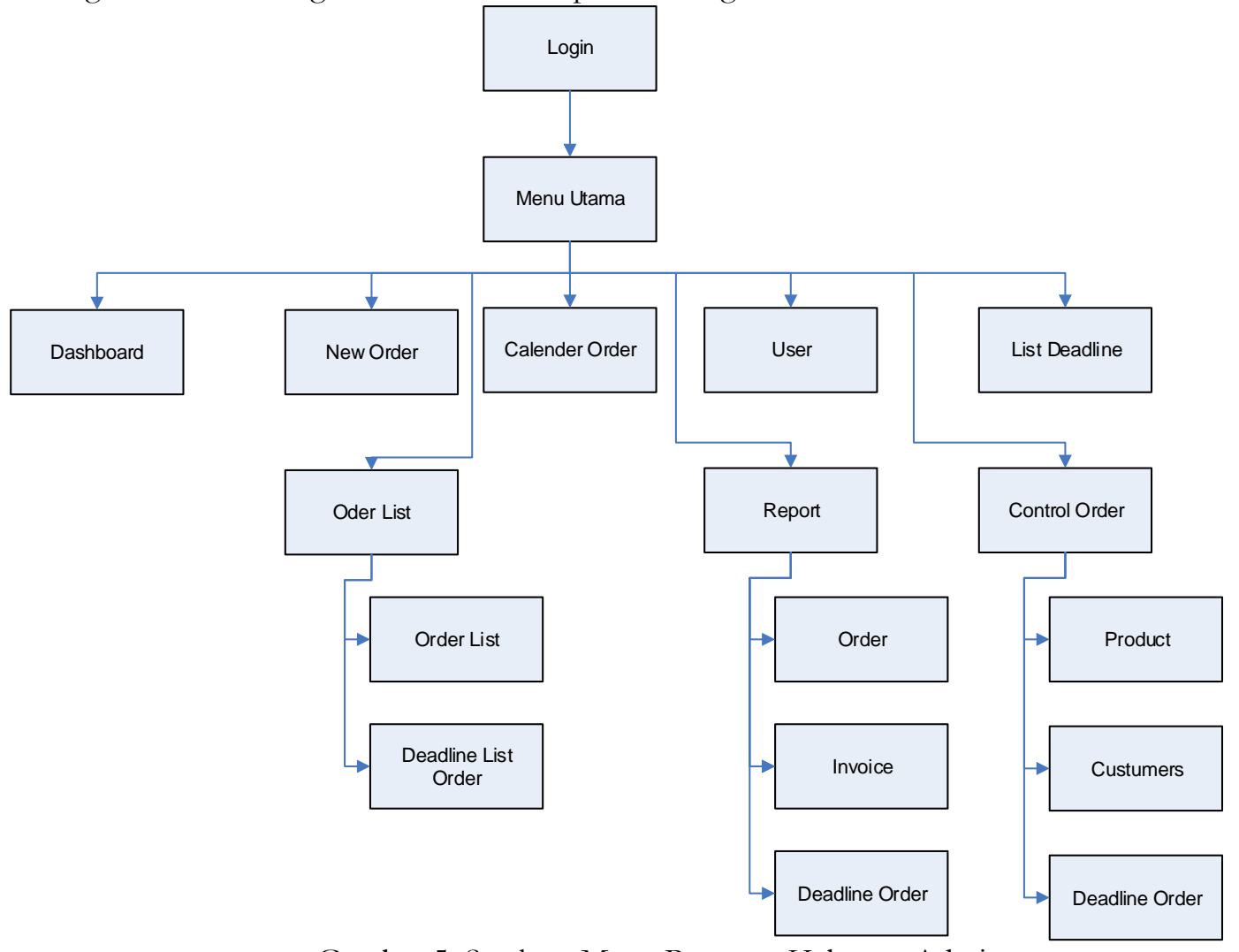

Gambar 5. Struktur Menu Program Halaman Admin

Sedangkan tampilkan hasil rancangan aplikasi terlihat pada gambar 6 berikut ini:

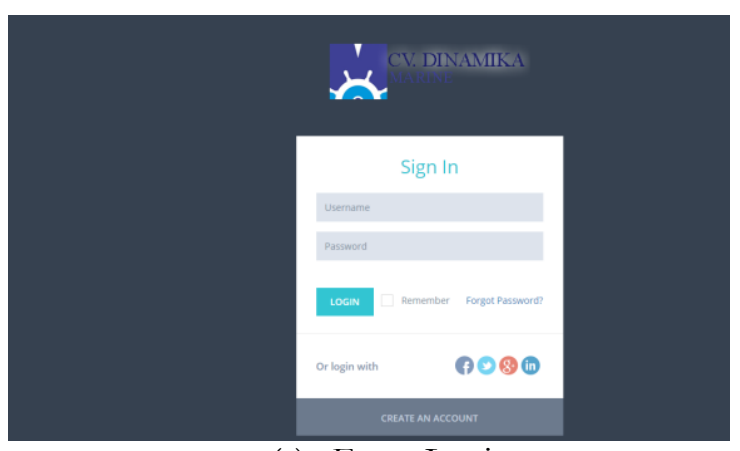

(a) Form Login

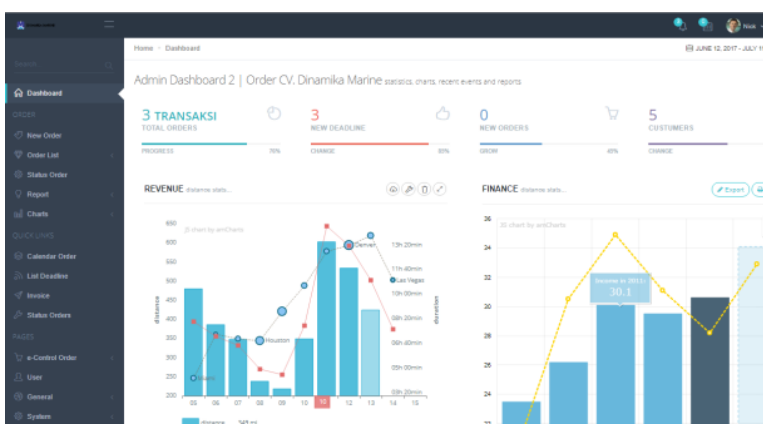

(b) Halaman Menu Utama 


\section{Jurnal Indonesia : Manajemen Informatika dan Komunikasi}

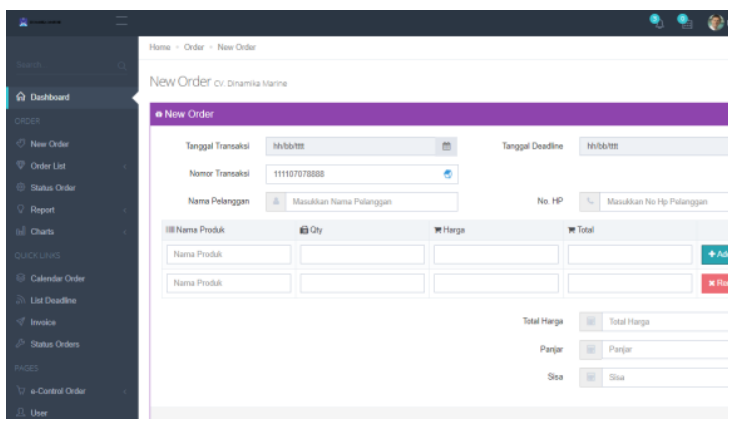

(c) Form Penjualan

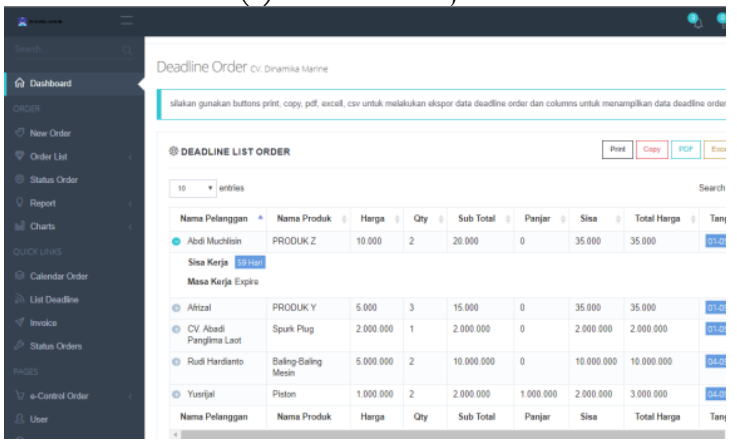

(e) Form Pemesanan yang belum terkirim
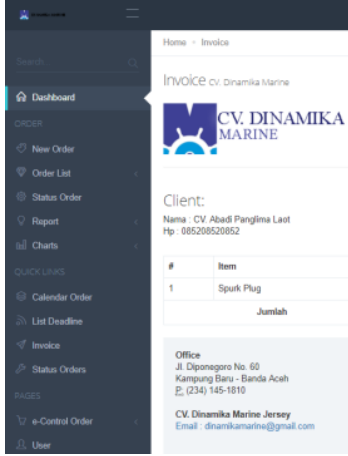

(g) Invoice

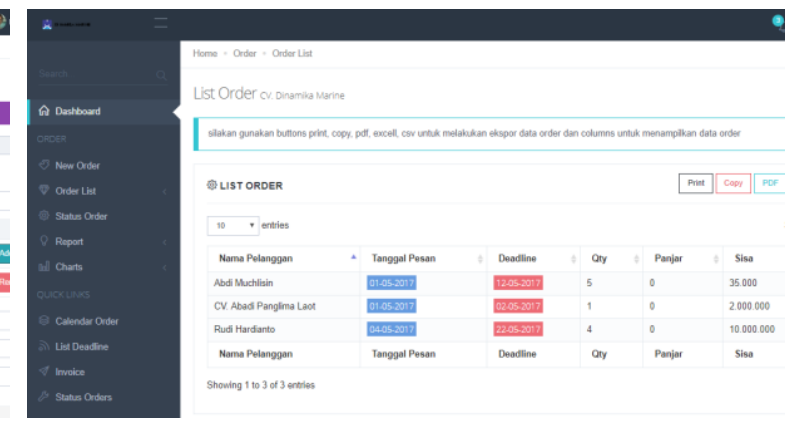

(d) Form Daftar Penjualan

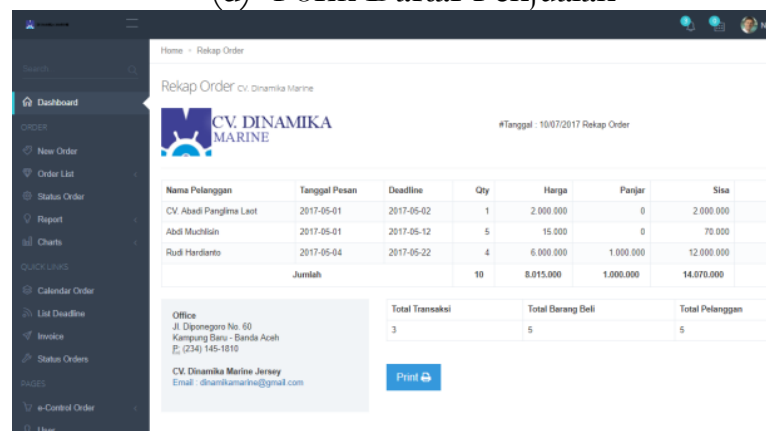

(f) Form Laporan Penjualan

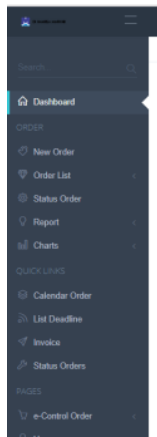

(h) Kalender Transaksi

Gambar 6. Hasil Rancangan

\section{Kesimpulan dan Saran}

Berdasarkan hasil penelitian dan penulis dapat menarik suatu kesimpulan yang diantaranya adalah sebagai berikut :

1) Aplikasi Penjualan Suku Cadang Mesin Outboat ini mempermudah dalam pengolahan data transaksi dan data stok barang berdasarkan penjualan, terlebih dahulu dilakukan analisa sistem lama, analisa kebutuhan pengguna, penganalisisan kelayakan sistem, perancangan desain sistem yang meliputi pemodelan proses dengan DAD sebagai alat bantu desain, pemodelan data dengan membuat rancangan tabel, dan perancangan antarmuka design interface dan dibangun menggunakan bahasa pemrograman berbasis web dengan database yang dibuat menggunakan MySQL.

2) Tingkat ketelitian aplikasi ini dalam hal pencatatan tranksaksi dan stok Suku Cadang Mesin Outboat dapat dilihat berdasarkan hari, bulan dan tahun tertentu sehingga dapat mengurangi tingkat kesalahan buman error. Aplikasi ini dapat menangani perubahan-perubahan yang terjadi, seperti perubahan harga dan penambahan jenis barang, perubahan-perubahan tersebut dapat dilakukan pengolahan pada form transaksi penjualan. Aplikasi bersifat sederhana, bahasa yang 
digunakan mudah dimengerti user, sehingga tidak memerlukan waktu yang lama untuk pelatihan dalam pengoperasian aplikasi ini. berikut :

Adapun saran yang ingin penulis sampaikan setelah melakukan pengamatan adalah sebagai

1) Aplikasi Penjualan Suku Cadang Mesin Outboat ini masih memerlukan pengembangan lebih lanjut agar menjadi aplikasi yang dapat mempermudah dalam melakukan aktivitas yang berhubungan dengan pencatatan berbagai macam transaksi penjualan.

2) Dalam pengembangannya diharapkan sistem ini juga mampu melakukan pemesanan dan transaksi secara online, dengan ketentuan pelanggan harus terkoneksi dengan internet. Penambahan gambar maupun animasi juga disarankan agar tampilan Aplikasi Penjualan Suku Cadang Mesin Outboat lebih menarik.

\section{Daftar Pustaka}

[1] Wali, M., 2019. Application Optimizing the Placement of Safety Stocks Using the Max-Min Method for Printing Companies. International Journal of Research and Review, 6(2), pp.203-210.

[2] Kadafi, M., 2020. SISTEM INFORMASI PENGOLAHAN DATA TRANSAKSI PADA CV. GLOBAL TRANS SOLUTIONS. Jurnal Indonesia: Manajemen Informatika dan Komunikasi, 1(1), pp.1-8.

[3] Ahmad, L., Wali, M., Akbar, R. and Syafwandhinata, J., 2020. IbM Pemberdayaan Generasi Muda melalui Enterpreneurship. Jurnal Pengabdian Nasional (PPN) Indonesia, 1(1), pp.30-36.

[4] Wali, M. and Ahmad, L., 2020. Source Code Library (SCL): Application Support Learning Software Development: Source Code Library (SCL): Application Support Learning Software Development. Jurnal Mantik, 4(1), pp.7-13.

[5] Ismail, I., Al-Bahri, F.P.F.P., Ahmad, L. and Salam, A., 2020. IbM Pelatihan Kewirausahaan Sebagai Upaya Menumbuhkan Jiwa Kewirausahaan dan Menggali Ide Usaha Baru. Jurnal Pengabdian Nasional (JPN) Indonesia, 1(1), pp.16-22.

[6] Ismail, I. and Syafwandhinata, J., 2020. IbM PELATIHAN, PEMBINAAN DAN PENDAMPINGAN BIDANG KERAJINAN, SOUVENIR, SABLON DAN PERCETAKAN. Bakti Banua: Jurnal Pengabdian Kepada Masyarakat, 1(1), pp.1-9.

[7] RIZAL, S. and WALI, M., 2019. The Effect of Leadership Style, Compensation and Organizational Commitment to Working Satisfaction of Aceh Social Service Employees. Editorial Board, p.797.

[8] Iqbal, T., Aprizal, D. and Wali, M., 2017. Aplikasi Manajemen Persediaan Barang Berbasis Economic Order Quantity (EOQ). Jurnal JTIK (Jurnal Teknologi Informasi dan Komunikasi), 1(1), pp.48-60.

[9] Mukhtar, M. and Wali, M., 2014. Sistem Harga Pokok Produksi dengan Pendekatan Job Order Costing dan Pengaruhnya Terhadap Laba Usaha. Jurnal Ekonomi Manajemen dan Bisnis (EMBis), 2(2), pp.345-355. 
[10] Rizal, S. and Wali, M., 2013. Dimensi Kesadaran Merek dan Keputusan Konsumen Memilih Hermes Palace Hotel di Kota Banda Aceh. Jurnal Ekonomi Manajemen dan Bisnis (EMBis), 1(1), pp.27-41.

[11] Wali, M., Iqbal, T. and Syafwandhinata, J., 2021. IbM Pelatihan, Pembinaan dan Pendampingan Penggunaan Aplikasi Management Stock Control. AJAD: Jurnal Pengabdian kepada Masyarakat, 1(1), pp.9-16.

[12] Salam, A. and Mujiburrahman, M., 2018. Pengendalian Persediaan Bahan Baku menggunakan Metode Min-Max Stock pada Perusahaan Konveksi Gober Indo. Jurnal EMT KITA, 2(1), pp.47-54.

[13] Wali, M., 2020. Modul Praktikum Rekayasa Perangkat Lunak. Ellunar Publisher.

[14] Irsandi, J.S., Fitri, I. and Nathasia, N.D., 2021. Sistem Informasi Pemasaran dengan Penerapan CRM (Customer Relationship Management) Berbasis Website menggunakan Metode Waterfall dan Agile. Jurnal JTIK (Jurnal Teknologi Informasi dan Komunikasi), 5(4), pp.346-353.

[15] Salam, A. and Ridha, R., 2019. Sistem Basis Data dengan Microsoft Office Access: Teori dan Praktikum. KITA Publisher. 